Relations industrielles

Industrial Relations

\title{
Le fondateur du syndicalisme catholique au Québec, Mgr Lapointe, par Robert Parisée, Montréal, Les Presses de l’Université du Québec, 1978, 80 pp.
}

\section{Gérard Dion}

Volume 34, numéro 1, 1979

URI : https://id.erudit.org/iderudit/028955ar

DOI : https://doi.org/10.7202/028955ar

Aller au sommaire du numéro

Éditeur(s)

Département des relations industrielles de l'Université Laval

ISSN

0034-379X (imprimé)

1703-8138 (numérique)

Découvrir la revue

Citer ce compte rendu

Dion, G. (1979). Compte rendu de [Le fondateur du syndicalisme catholique au Québec, Mgr Lapointe, par Robert Parisée, Montréal, Les Presses de l'Université du Québec, 1978, 80 pp.] Relations industrielles / Industrial Relations, 34(1), 210-210. https://doi.org/10.7202/028955ar

Tous droits réservés (C Département des relations industrielles de l'Université Laval, 1979
Ce document est protégé par la loi sur le droit d'auteur. L'utilisation des services d'Érudit (y compris la reproduction) est assujettie à sa politique d'utilisation que vous pouvez consulter en ligne.

https://apropos.erudit.org/fr/usagers/politique-dutilisation/ 
lité volontaire du salarié et de son coût, est elle-même limitée.

Il faudra sans doute ré-introduire certains éléments de l'analyse «institutionnaliste" tels la relation entre formation en cours d'emploi et processus de socialisation dans le milieu de travail, instabilité d'emploi et organisation (formelle ou informelle) du «job temtory», salaires et structures sociales de rémunération.

\section{Jacques MERCIER}

Université Laval

Le fondateur du syndicalisme catholique au Québec, Mgr Lapointe, par Robert Parisée, Montréal, Les Presses de l'Université du Québec, 1978, 80 pp.

Mgr Eugène Lapointe est certainement une grande personnalité qui a imprimé sa marque sur le développement de la pensée et de l'action sociales de la région du Saguenay au début du siècle. Son zèle, son dévouement pour l'amélioration de la condition des classes laborieuses ont inspiré beaucoup d'autres apôtres sociaux à œuvrer dans ce domaine. Il est devenu un personnage légendaire.

L'auteur nous avertit que «son ouvrage a pour objectif d'exposer systématiquement la pensée et l'action de $\mathrm{Mgr}$ Eugène Lapointe dans le domaine syndical exclusivement" et qu'il repose, pour l'essentiel sur un travail de recherche effectué aux archives de la Société historique du Saguenay.

Six très brefs chapitres constituent l'ouvrage. Ceux qui ont connu $\mathrm{Mgr}$ Lapointe resteront sur leur appétit. Quant aux autres, je crains qu'ils ne pourront jamais s'expliquer pourquoi Mgr Lapointe a pu jouir d'une telle réputation.

Ce n'est pas une étude fouillée ni systématique de la pensée du personnage. On n'y apprend pas beaucoup plus que ce que l'on trouve dans l'article de Michel Têtu publié dans Relations industrielles en 1962.

Faute d'être replacées dans leur contexte idéologique et historique, les conceptions et les positions de Mgr Lapointe peuvent difficilement être comprises par le lecteur contemporain et risquent plutôt de discréditer le personnage et son auvre.

Répéter aujourd'hui que Mgr Lapointe a été le fondateur du syndicalisme catholique au Québec, ce n'est pas simplement une exagération mais c'est une erreur. En effet, malgré les bonnes intentions et le dévouement de son fondateur, la Fédération ouvrière de Chicoutimi de 1907 n'était pas à proprement parler du syndicalisme, mais simplement une société mutuelle dont l'efficacité a été douteuse et dont la durée a été éphémère. Constater cette vérité, ce n'est pas une injure à la mémoire de $\mathrm{Mgr}$ Lapointe; ce n'est pas non plus nier le travail qu'il a accompli, car celui-ci donnera ses fruits plus tard et la région du Saguenay deviendra un des foyers les plus actifs du syndicalisme catholique au Québec.

Il aurait été intéressant d"expliquer comment $\mathrm{Mgr}$ Lapointe en était venu à sa conception d'action ouvrière qu'il considérait comme du syndicalisme, où il avait pris ses sources d'inspiration, à quelle école de pensée il se rattachait, pourquoi il avait choisi cette école plutôt qu'une autre, quels problèmes cela lui a causé au Québec avec d'autres penseurs sociaux instigateurs du syndicalisme catholique qui appartenaient à une autre école, comme l'abbé Maxime Fortin et Alfred Charpentier, etc. Mais pour en arriver là, l'auteur aurait du pousser ses recherches au delà des archives personnelles de $\mathrm{Mgr}$ Lapointe qui, tout intéressantes qu'elles soient, m'apparaissent assez limitées.

Cet ouvrage relève beaucoup plus de la littérature édifiante que de l'histoire. Mgr Lapointe aurait mérité mieux que cela.

Gérard DION

Université Laval

The Role of Trade Unions in Developing Societies, by Everett M. Kassalow and Ikanig Damachi (Eds), Geneva, International Institute for Labour Studies, $1978,183 \mathrm{pp}$.

Les études sur le syndicalisme dans les pays en voie de développement ont 